\title{
Chemical leaching characteristics of umber ore samples showing their forming processes
}

\author{
YUtARO TAKAYA ${ }^{1,2,3,4, *}$, KOICHIRO FUJINAGA ${ }^{2,4}$, \\ TATSUO NOZAKI ${ }^{3,4,5,2}$, AND YASUHIRO KATO ${ }^{4,2,3}$ \\ ${ }^{1}$ Waseda University \\ ${ }^{2}$ Chiba Institute of Technology \\ ${ }^{3}$ Japan Agency for Marine Earth Science and Technology \\ ${ }^{4}$ The University of Tokyo \\ ${ }^{5}$ Kobe University \\ *y-takaya@aoni.waseda.jp
}

REEs (rare earth elements) are essential materials for cutting-edge industries such as green technology and medical technology, and their global demands are predicted to increase in the next few decades. In recent years, the exploration of new REE mines including seafloor mineral resources for the stable supply is actively engaged worldwide.

Strata-bound ferromanganese deposits on land, known as umber deposit, have recently attracted attention as a new REE resource [1-3]. These deposits are of hydrothermal metalliferous sedimentary origin and have reraltively high total REE contents ( $\Sigma \mathrm{REE} \sim 2,000 \mathrm{ppm}$ ). Here, we conducted chemical leaching experiments on three different umber ore samples, two of them (Kuminiyama and Aki umber) were collected from Japanese accretionary complexes of southwestern Japan and the other (Cyprus umber) from Troodos ophiolite, to elucidate their forming processes and to optimize the REE extraction process. The three umber ore samples had a wide range of chemical/mineral compositions as well as physical properties, and showed different leaching behaviors. Our experimental results demonstrated that the physical properties (density and P-wave propagation velocity) principally controlled the extent of REE extraction rate, and REE extraction rate from umber samples clearly increased with the decrease in the density and $\mathrm{P}$-wave propagation velocity. The differences in physical properties of the umber samples are attributable to the pressure and thermal history of each ore sample along with obduction/subduction processes, and it was revealed that umber samples which underwent strong metamorphism are not suitable for actual development because of the dense texture and low REE extraction rate.

[1] Kato et al. (2005) Resour. Geol., 55, 291-299. [2] Josso et al. (2018) Miner. Eng., 118, 106-121. [3] Takaya et al. (2019) Minerals, 9, 239. 